\title{
Alley-cropping system can boost arthropod biodiversity and ecosystem functions in oil palm plantations
}

\begin{abstract}
Oil palm (Elaeis guineensis) is among the fastest expanding crops, due to high global demand for vegetable oils. Large areas of forest are converted into oil palm plantation to meet the market demand in producing countries which causes rapid decline in tropical biodiversity, including arthropods. The alley-cropping system has the potential to promote faunal biodiversity, related ecosystem services and food security in agricultural landscapes. In alleycropping, a main crop is intercropped with a secondary crop (often a food crop), secondary crops are cultivated in the alleys in between the main crop. We compared arthropod taxonomic richness, arthropod predators and decomposers between five alley-cropping treatments (pineapple, bamboo, black pepper, cacao, bactris), where oil palm is intercropped with another species. In addition, we sampled two control treatments: monoculture oil palm, aged seven and 15 years old. A total of 50,155 arthropod individuals were recorded using pitfall trap sampling, representing 19 orders and 28 families. Fourteen orders belonging to sub-phylum Insecta, three orders from Arachnida (Araneae; Acarinae; Scorpiones) and two orders from Myriapoda (Chordeumatida; Geophilomorpha). We detected an increase in beta-diversity of oil palm production landscape. Specifically, we found that the number of arthropod orders, families and abundance were significantly greater in alley-cropping farming plots than those in monoculture plots. In addition, alley-cropping treatments contained larger numbers of predators and decomposers. Our findings suggest that the alley-cropping system can become a key management strategy to improve biodiversity and ecosystem functions within oil palm production landscapes.
\end{abstract}

Keyword: Agroforestry; Biodiversity; Conservation; Insects; Monoculture; Oil palm 